\title{
Removal of basic and reactive dyes using ethylenediamine modified rice hull
}

\begin{abstract}
Wastewaters from textile industries may contain a variety of dyes that have to be removed before their discharge into waterways. Rice hull, an agricultural by-product, was modified using ethylenediamine to introduce active sites on its surface to enable it to function as a sorbent for both basic and reactive dyes. The sorption characteristics of Basic Blue 3 (BB3) and Reactive Orange 16 (RO16) by ethylenediamine modified rice hull (MRH) were studied under various experimental conditions. Sorption was $\mathrm{pH}$ and concentration dependent. Simultaneous removal of BB3 and RO16 occurred at $\mathrm{pH}$ greater than 4 . The kinetics of dye sorption fitted a pseudo-second order rate expression. Increase in agitation rate had no effect on the sorption of BB3 but increased uptake of RO16 on MRH. Decreasing particle size increased the uptake of dyes in binary dye solutions. Equilibrium data could be fitted into both the Langmuir and Freundlich isotherms. Maximum sorption capacities calculated from the Langmuir model are 14.68 and $60.24 \mathrm{mg} / \mathrm{g}$ for BB3 and RO16, respectively in binary dye solutions. This corresponds to an enhancement of 4.5 and 2.4 fold, respectively, compared to single dye solutions. MRH therefore has the potential of being used as an efficient sorbent for the removal of both dyes in textile wastewaters.
\end{abstract}

Keyword: Sorption; Rice hull; Ethylenediamine; Reactive dyes; Basic dyes 